\title{
The Human Locus Coeruleus: Computer Reconstruction of Cellular Distribution
}

\author{
D. C. German, ${ }^{1,2}$ B. S. Walker, ${ }^{1}$ K. Manaye, ${ }^{1}$ W. K. Smith, ${ }^{3}$ D. J. Woodward, ${ }^{3}$ and A. J. North \\ Departments of ${ }^{1}$ Psychiatry, ${ }^{2}$ Physiology, and ${ }^{3}$ Cell Biology and Anatomy, University of Texas Health Science Center at \\ Dallas, Dallas, Texas 75235
}

\begin{abstract}
Quantitative neuroanatomical techniques were developed to map the distribution of norepinephrine-containing locus coeruleus (LC) neurons in the adult human brain. These neurons reside in the darsolateral pontine tegmentum and are identifiable by their neuromelanin pigment content. Five brains, ranging in age from 60 to 104 years, were examined. Outlines of coronal or sagittal sections containing the LC were entered into a computer along with the location of each cell, certain neuroanatomical landmarks, and cell size. Sections were aligned with specific neuroanatomical landmarks so that the computer-generated distribution of cells was representative of the in situ distribution of cells. Analysis of (1) the number of cells in sections throughout the rostrocaudal extent of the nucleus, (2) cell size, (3) 3-dimensional reconstructions of the distribution of cells within the brain stem, and (4) 2-dimensional cell-frequency maps, make it possible to quantitatively characterize the distribution of cells within this large nucleus. The total estimated number of LC cells on both sides of the brain ranged from 45,562 to 18,940 (youngest to oldest), and mean soma area ranged from 835 to $718 \mu \mathrm{m}^{2}$ (youngest to oldest). The nucleus is "tube-like" in shape, has a rostrocaudal extent of approximately $16 \mathrm{~mm}$, and is bilaterally symmetrical. Two-dimensional cell-frequency maps were developed to illustrate the regional distribution of cell frequencies at any rostrocaudal/mediolateral point on the horizontal plane; the total unilateral area of the LC ranged from 32.8 to $17.2 \mathrm{~mm}^{2}$ (youngest to oldest). The techniques developed to characterize the 2- and 3-dimensional distributions of LC neurons can be used in future studies to quantitatively examine the effects of aging and disease on this and other brain nuclei.
\end{abstract}

The locus coeruleus (I.C), or blue spot, was identified (Reil, 1809) and named (Wenzel and Wenzel, 1811) in the human brain over 175 years ago. This nucleus is the largest collection of norepinephrine-containing neurons in the mammalian brain (Dahlstrom and Fuxe, 1964; Ungerstedt, 1971; Nobin and Björklund, 1973; Olson et al., 1973; Choi et al., 1975). These cells have been studied in numerous species (e.g., several primates, dog, cat, rabbit, horse, sea lion, sheep, muskrat, bat, owl;

\footnotetext{
Received May 20, 1987; revised Sept. 4, 1987; accepted Sept. 26, 1987.

This work was supported by grants from the National Institutes of Health (MH 30546, NS-20030, DA-2338), the David Bruton Jr. Charitable Trust and the Biological Humanics Foundation. We wish to thank Ms. Laura Boynton for secretarial assistance and $\mathrm{Mr}$. S. Askari for histological assistance.

Correspondence should be addressed to Dr. Dwight C. German, Department of Psychiatry, University of Texas Health Science Center, Dallas, TX 75235-9070. Copyright (C) 1988 Society for Neuroscience $0270-6474 / 88 / 051776-13 \$ 02.00 / 0$
}

see Russell, 1955, for review), but most extensively in the rat (see Moore and Bloom, 1979, for review). The neurons begin rostrally at the level of the inferior colliculus in the ventrolateral central gray and continue caudally to the region of the lateral wall of the fourth ventricle. The rat has an estimated $1600 \mathrm{LC}$ neurons on each side of the brain (Swanson, 1976; Loughlin et al., 1986), which give rise to axons that project to the entire cerebral cortex, several subcortical nuclei, cerebellar cortex, and spinal cord (see Moore and Bloom, 1979, for review). Similar projections have been reported in the primate (Freedman et al., 1975; Bowden et al., 1978; Westlund et al., 1984).

The number of human LC neurons has been shown to decrease with normal aging and as a result of certain diseases. By the ninth decade of life there is a $25-60 \%$ loss of $\mathrm{LC}$ neurons (Vijayshankar and Brody, 1979; Tomlinson et al., 1981; Mann et al., 1983). With Parkinson's disease, there is a loss of LC neurons in addition to the loss of midbrain dopaminergic neurons (Hornykiewicz, 1979; Mann and Yates, 1983; Mann et al., 1983). With Alzheimer's disease there is also a marked loss of cells and an accumulation of neurofibrillary tangles within the LC (Forno, 1978; Mann et al., 1980, 1983; Tomlinson et al., 1981; Iversen et al., 1983; German et al., 1987).

The purpose of the present study was to use newly developed computer imaging techniques (Schlusselberg et al., 1982) to map and quantify the spatial distribution of $\mathrm{LC}$ neurons in the normal human brain. The present paper describes the computer-assisted neuroanatomy methods that have made possible, for the first time, an accurate 2- and 3-dimensional description of the spatial distribution of $\mathrm{LC}$ neurons in the adult human brain.

\section{Materials and Methods}

Brain material/histology. Human brains were received from the Dallas County Medical Examiner at the University of Texas Health Science Center at Dallas. The brains came from individuals with no reported history of neurological or psychiatric disease and appeared grossly normal at autopsy. Brains were received within $15 \mathrm{hr}$ after death and they were immersion-fixed in $10 \%$ neutral-buffered formalin (NBF). During fixation, each brain was suspended in NBF by a string tied to the basilar artery. This allowed it to fix with minimal distortion of its natural shape. Each brain was weighed, and, after approximately 1 week, the brain stem (from the level of the caudal diencephalon to the caudal medulla) was dissected out and fixed in fresh NBF for an additional 2-4 weeks.

Frozen sections were cut at $50 \mu \mathrm{m}$ thickness using a sliding microtome. In 4 brains the sections were cut perpendicular to the long axis of the brain stem (coronal sections), and in one brain the sections were cut parallel to the midsagittal plane of the brain stem (sagittal sections). During the blocking of the brain stem and the cutting of the sections, every attempt was made to cut the sections in an exact coronal or sagittal plane. Sections were mounted on glass slides and care was taken to mount the section flat onto the slide so as to preserve, as much as 
possible, the normal cytoarchitectonic relationships among nuclear groups. One coronal series of sections within each brain (every sixteenth section, or $0.8 \mathrm{~mm}$ apart) was stained for Nissl substance (using cresyl violet) and another for neuromelanin (using Schmorl's ferricyanide; Lillie, 1954). Sagittal sections were stained for Nissl substance and examined at $0.2 \mathrm{~mm}$ intervals.

Computer-aided anatomy. The computer graphics system consists of a Leitz Ortholux II microscope with a computer-driven stage (Bunton Instruments, Model EK 8b) and drawing tube, which is interfaced to a Data General DeskTop 10SP computer equipped with a digitizing table (BitPad II). Data generated from this system were subsequently analyzed with an Adage 3000 color raster graphics system and a Data General MV/8000 II computer.

Tissue sections containing LC cells were projected, using a photographic enlarger (Beseler Dual Dichro S), onto the surface of a digitizing tablct. The outlines of the section, the cerebral aqueduct and fourth ventricle, were entered into the computer. For each section, one coordinate point was entered into the computer to mark the ventralmost midline point within the cerebral aqueduct/fourth ventricle, and a second coordinate point marked the location of the ventralmost midline point of the pons. These points were later used to align the sections to a common vertical midline plane. The section was then put on the microscope stage and the coordinate points were reentered. This procedure allowed low-power drawings of macrostructures to be merged with data obtained using the high-power precision coordinate system of the microscope stage.

Mapping of cellular locations ( $16 \times$ objective, $12.5 \times$ eyepiece, $1.25 \times$ drawing tube) occurred at a final magnification of $250 \times$. Information concerning the anatomical boundaries of the $\mathrm{LC}$ was entered into the computer to define the scanning area. The stepper-stage motors were given commands to move to locations within the biological coordinate system that contained the pigmented LC neurons. The operator, looking at the section in the microscope, saw a rectangular box around a critical area. A button-cursor system on the digitizing tablet was programmed to control a small, bright triangular cursor seen in the field of view. The cursor was successively positioned on top of each LC neuron and the button was pressed to record the cell location. A small triangle appeared on top of each cell when its position had been recorded. When all cells in the box had been recorded, the stepper stage moved to an adjacent location and a new box was drawn in the field of view, along with the viewable data in the neighboring boxes. The computer scanned a grid system designed to include all cells within a given section.

LC cells were defined as neuromelanin pigment-filled masses enclosed by a cell membrane. Many of the cells contained a visible nucleus, but cells without visible nuclei were also counted. Glial cells often contained pigment, marking the location of neuronal death, but they are too small to be counted as LC cells. In the coronal series, data from 17-22 sections were entered into the computer. In the sagittal series, data from 35 sections were entered into the computer. Information concerning the distance between sections ( 0.8 or $0.2 \mathrm{~mm} Z$ values) was also entered into the computer.

Section alignment. Before the data were analyzed further, it was necessary to align the sections so that the cellular reconstructions would be representative of the normal position of the cells within the intact brain. A 2-part procedure was employed, one at low-power magnification (taking advantage of the global features of the tissue section) and the other at higher power (focusing specifically upon microalignment of the cells). In the case of the coronal sections, the most caudal section was displayed on the video monitor first and positioned so that the midline axis was oriented vertically. Next, sections were displayed 2 at a time on the video monitor with each section and corresponding LC cells displayed in different colors (i.e., the caudal section and cells were displayed in red, while the rostral section and cells were displayed in blue). The rostral section was moved (up, down, left, right, or rotated) such that the section outline, the LC cellular positions, and the outlines of the cerebral aqueduct or fourth ventricle were superimposed upon the corresponding elements in the caudal section. Once all sections in the series were so aligned, the second alignment procedure was employed. At a microscopic level, using graphics visualization of cell groupings, it was possible to see small discontinuities whenever misalignment appeared. Microalignment procedures could take advantage of the visual shape of the reconstructed cell populations. As a rule, the cellular distributions assumed a smooth shape when local alignment was optimal. Shapes observed in both coronal and sagittal series were similar after optimal microalignment was carried out. This fact served to validate the alignment procedure. A similar strategy was used to align the sagittal sections.

Computer reconstruction functions. Four major functions were performed by the computer visualization system. (1) Cell locations within each section were plotted with respect to their biological position within the brain, and cell counts were generated for specified regions. (2) Cell size meausrements (areas) were calculated after outlines of cell perimeters, observed in Nissl-stained sections, were digitized and stored in the computer. Using $625 \times$ magnification, outlines were drawn around each pigment-containing soma that had a clearly visible nucleus. Outlines were drawn around cells in one section from each of the 4 coronally sectioned brains through comparable portions of the nucleus. The middle region of the LC, which contains the highest number of cells per section, was chosen as the region in which to measure cell size. (3) Three-dimensional reconstructions of the distribution of LC cells within the brain stem were generated. Surfacing algorithms were developed to illustrate the cells as spheres. The cells were displayed in each section entered into the computer, along with outlines of the section perimeter, cerebral aqueduct, or fourth ventricle. The sections were displayed 0.8 $\mathrm{mm}$ apart, in the case of the coronally sectioned brains, or $0.2 \mathrm{~mm}$ apart, in the case of the sagittally sectioned brains. In the former brains, the sections were aligned to a $90^{\circ}$ vertical plane perpendicular to the long axis of the brain stem. In the latter brains, the sections were aligned to a $90^{\circ}$ vertical plane parallel to the long axis of the brain stem. The reconstructed nucleus could be viewed from any designated angle to visualize the cellular distribution within the brain stem. (4) A form of spatial-density map, here termed a cell-frequency map, was created on the horizontal $(x-z)$ plane by collapsing the 3-dimensional distribution of cells onto this 2-dimensional plane. These cell-frequency maps were generated from the 3-dimensional reconstructions by first creating cellfrequency histograms of the number of cells within successive $250 \mu \mathrm{m}$ vertical columns (or bins) across the mediolateral extent of each coronal section (or across the rostrocaudal extent in each sagittal section). Next a surface was formed from polygons spanning the midpoints of all adjacent bins (i.e., connecting adjacent mediolateral and rostrocaudal bins). Finally, the frequency of cells within the bins were color-coded on a 5-point scale, the magnitude of which was determined by the largest single bin frequency $(C)$ in any of the $0.25 \mathrm{~mm}$ bins $(B)$ from all of the brains that were examined. This number, along with the section thickness $(S ; 0.05 \mathrm{~mm})$ and a correction factor $(C F)$ for split-cell error, was used to calculate the maximum (Max) number of cells $/ \mathrm{mm}^{2}$, using the formula,

$$
\operatorname{Max}=C F \times C /(B \times S) .
$$

Five levels of cell frequency were chosen, each representing one-fifth of the Max, and each level was assigned a color value. The maps were viewed from a position above the long axis of the brain stem. This procedure allows a visual appreciation of the location of areas in the nucleus that contain different frequencies of cells. The total overall range of frequencies was $1-3200$ cells $/ \mathrm{mm}^{2}$.

\section{Results}

The LC was examined in 5 brains. Table 1 summarizes the general characteristics of these brains. The ages were $60,64,72$, 76 , and 104 years. The brains ranged in weight from 1100 to $1720 \mathrm{gm}$.

The $\mathrm{LC}$ is located in the dorsolateral pontine tegmentum (Fig. 1). The LC cells contain the black granular neuromelanin pigment (Fig. 1D), which makes them distinguishable from nearby nonpigmented cells, such as those in the mesencephalic nucleus of the trigeminal nerve. A map of the location and number of LC cells at representative levels throughout the rostrocaudal extent of the nucleus is shown in Figure 2. Note that the cells begin rostrally at the level of the inferior colliculus adjacent to the cerebral aqueduct and end caudally near the lateral wall of the fourth ventricle. The nucleus subcoeruleus extends ventrolaterally from the caudal pole of the LC (Fig. 2F). Over 200 cells may be observed in a single $50-\mu \mathrm{m}$ thick section in the most dense caudal portions of the nucleus. 
A

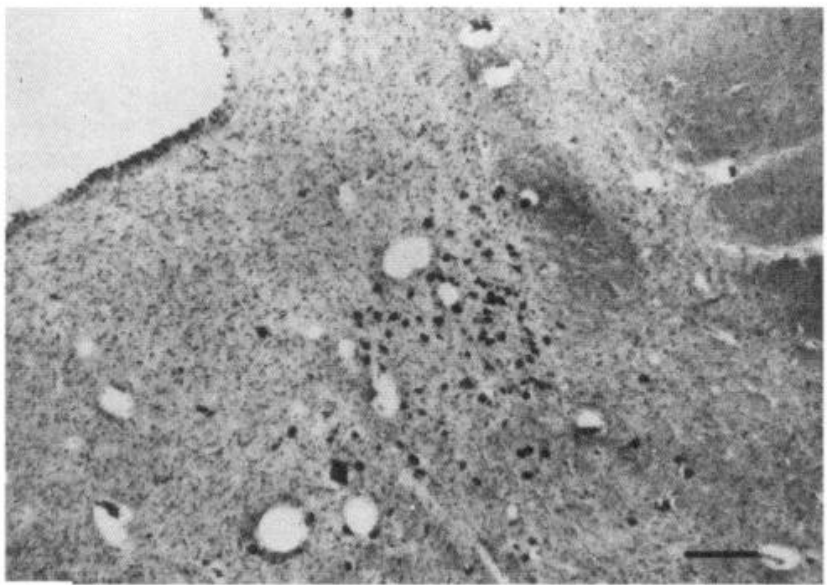

B

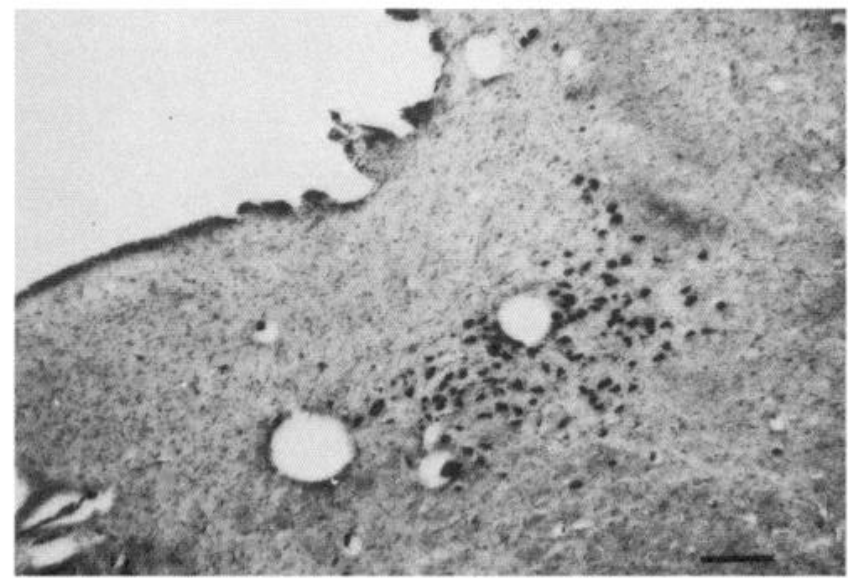

C

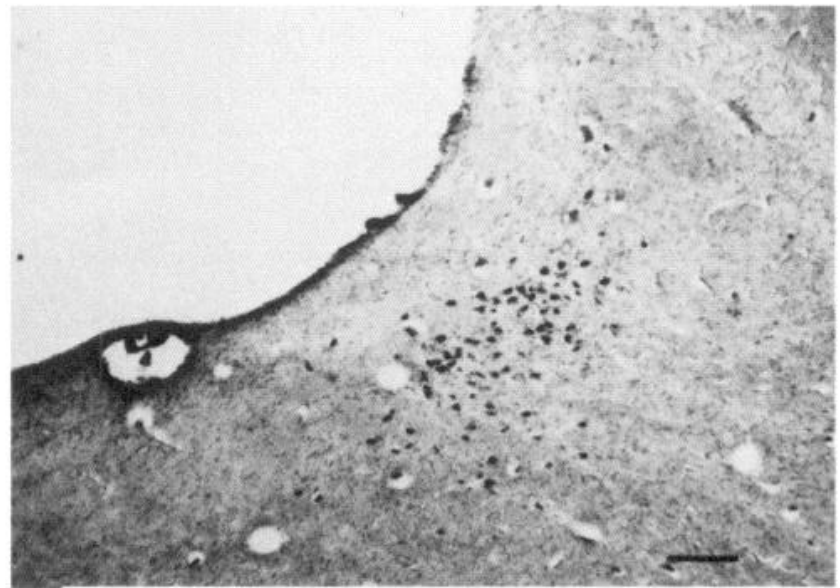

D

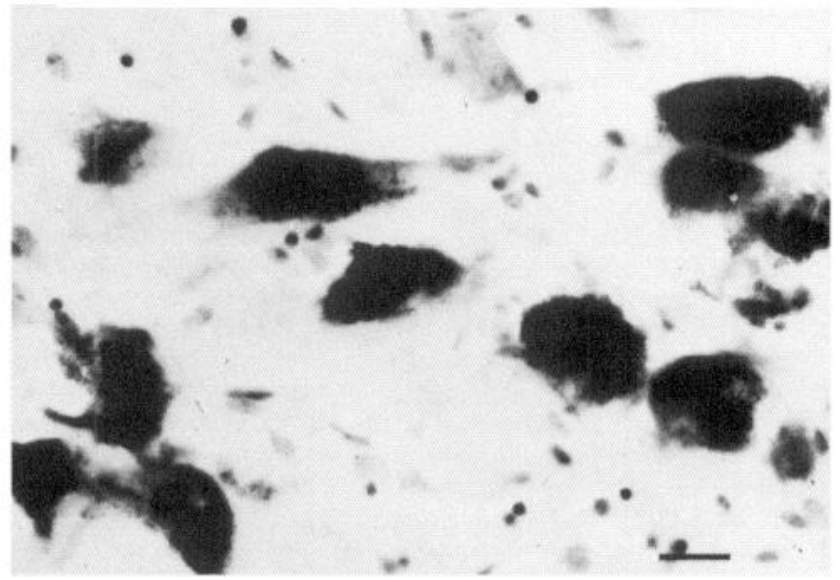

Figure 1. Photomicrographs of coronal sections through the LC. Low-power views of the pigmented cells in the right LC at 3 rostral $(A)$-caudal (C) pusitions within the dorsolateral pontine tegmentum. The cerebral aqueduct is present rostrally $(A$, upper left) and expands into the fourth ventricle caudally $(C) . A$, is $3.3 \mathrm{~mm}$ rostral to $B$, which is $4.3 \mathrm{~mm}$ rostral to $C$. Bar, $270 \mu \mathrm{m}(A-C)$. $D$, High-power view of LC cells, showing the dark granular neuromelanin pigment within the cells. Bar, $25 \mu \mathrm{m}$. Sections are from brain DA-34 and are stained with cresyl violet.

In the 4 coronally sectioned brains, the LC cells decreased in size with aging. As shown in Table 2, the soma cross-sectional areas ranged from 718 to $835 \mu \mathrm{m}^{2}$, and the 3 younger brains had significantly larger cells than did the oldest brain. Figure 3 illustrates soma sizes and shapes within the LC. The cells tended to be oval to fusiform in shape, and caudally they were often oriented with their long axis extending from ventromedial to dorsolateral. Figure 3 shows the outlines of all cells counted.

Table 1. Summary brain statistics

\begin{tabular}{lllll} 
Brain & $\begin{array}{l}\text { Age } \\
\text { (years) }\end{array}$ & Race & Sex & $\begin{array}{l}\text { Brain } \\
\text { weight } \\
\text { (gm) }\end{array}$ \\
\hline DA-33 & 60 & W & M & 1430 \\
DA-34 & 64 & B & M & 1330 \\
DA-39 & 72 & W & F & 1260 \\
DA-24 & 76 & W & M & 1720 \\
DA-47 & 104 & W & F & 1100 \\
\hline
\end{tabular}

In order to determine the normal variability in cell number between adjacent sections, we counted the total number of cells on one side of the brain in 59 consecutive sections at the caudal portion of the LC (Fig. 4). This portion of the nucleus included both the lowest and highest cell-frequency regions. There was not a completely smooth distribution of cells from section to section. As the number of cells increased per section, there was a greater variability in the number of cells in adjacent sections. Using a polynomial regression analysis we found that there was, on the average, a variability (standard deviation) of \pm 10 cells about a regression line that described the form of the distribution.

One issue to be resolved was the determination of how few sections needed to be counted in order to derive an accurate estimate of total cell number. Two techniques were used to assess this number. First, 49 consecutive sections were used to examine the effects of varying the distance between section samples on the accuracy of predicting cell numbers. For each distance between sections (i.e., every 4 th, 8 th, and 16 th section), a separate polynomial regression equation was derived from the 

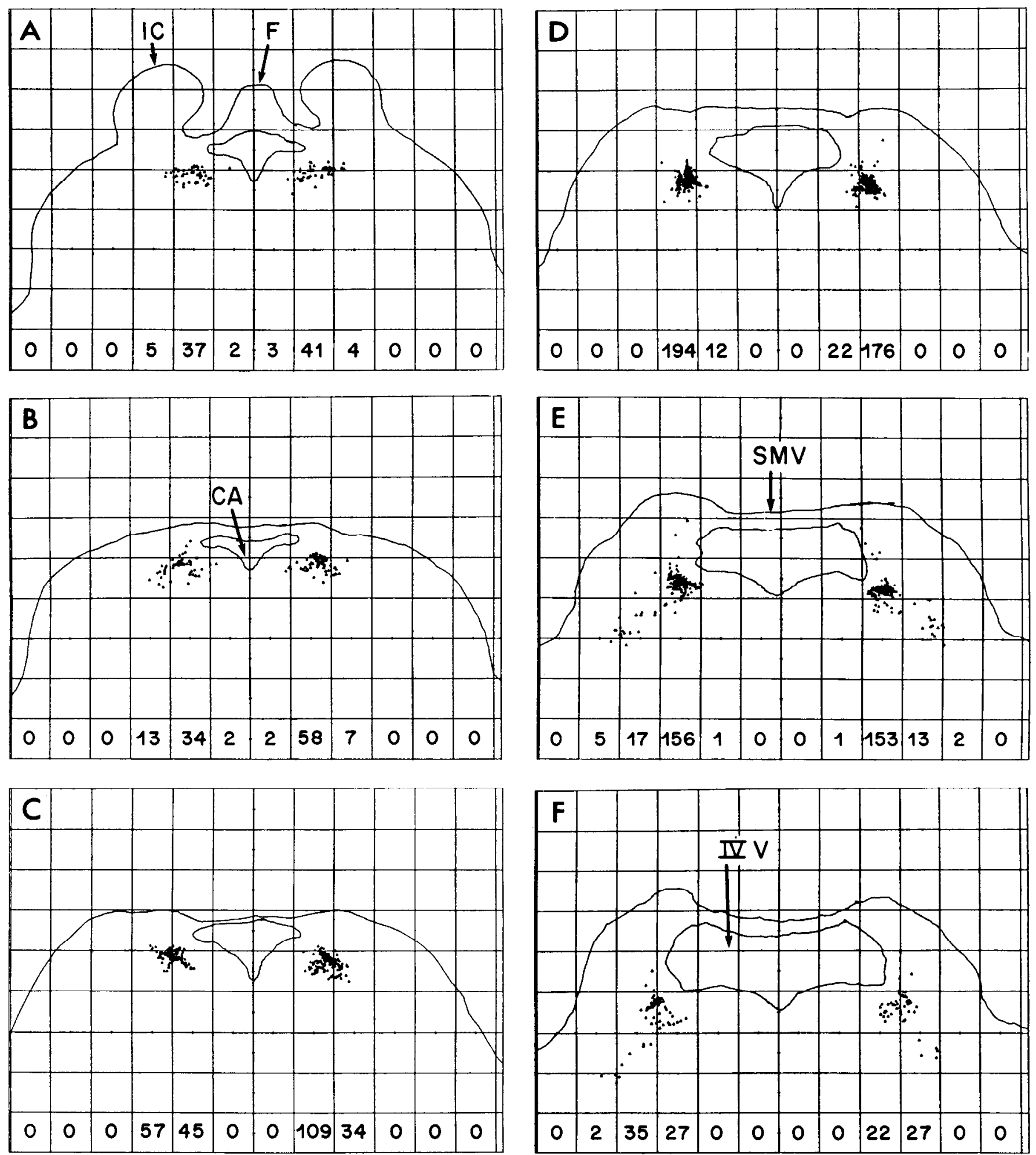

Figure 2. LC cell locations from rostral $(A)$ to caudal $(F)$. Each section is separated by $2.4 \mathrm{~mm}$ and each cell is illustrated as a dot. The cells begin rostrally, at the level of the inferior colliculus $(I C)$ and frenulum $(F)$, in a position lateral to the cerebral aqueduct $(C A)$. The cells are displaced laterally as the aqueduct expands into the fourth ventricle $(I V V)$. Grid size, $2 \mathrm{~mm}$. The number of LC cells in each column appears at the bottom of each panel. $S M V$, superior medullary velum.

limited set of observations under consideration. Then each such equation was used to estimate the number of cells in each of the 49 sections as well as the mean number of cells per section. As shown in Table 3, even after sampling every 16 th section, i.e., every $0.8 \mathrm{~mm}$, there was less than a $5 \%$ difference between the predicted and the observed number of cells per section. Second, we compared the cell-frequency distributions obtained by counting 2 adjacent series of sections separated by $0.8 \mathrm{~mm}$. 


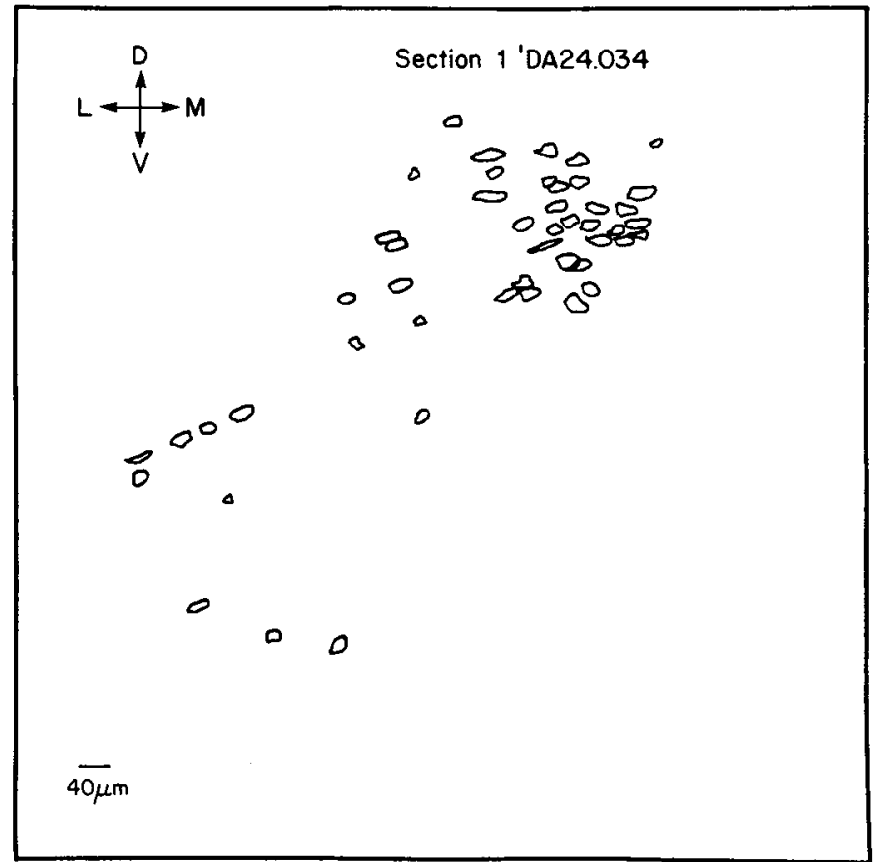

Figure 3. LC cell shapes from the left side of brain DA-24. A few subcoeruleus cells are shown ventrolateral to the LC. The cells are oval and fusiform in shape.

One series of sections was stained for Nissl substance (e.g., sections $0,16,32$, etc.) and compared with the adjacent sections stained with Schmorl's ferricyanide (e.g., sections 1, 17, 33, etc.) (Fig. 5). With 22 sections in each series, there was a total of 1950 cells counted in the left LC and 2099 in the right LC in the Nissl-stained sections, and 2012 cells in the left LC and 2029 cells in the right $\mathrm{LC}$ in the Schmorl's-stained sections. These cell counts differed by less than $4 \%$. Correlation coefficients comparing the cell frequencies on the left side of the brain (left Nissl versus left Schmorl's) with those on the right side of

\begin{tabular}{lcll}
\hline Table 2. & LC cell size & & \\
& & $\begin{array}{l}\text { Number of } \\
\text { cells measured }\end{array}$ & $\begin{array}{l}\text { Mean cell } \\
\text { area } \pm \text { SEM } \\
\left(\mu \mathrm{m}^{2}\right)\end{array}$ \\
\hline Brain & Age (years) & $835 \pm 27^{*}$ \\
DA-34 & 64 & 38 & $815 \pm 33^{*}$ \\
DA-39 & 72 & 42 & $790 \pm 25^{*}$ \\
DA-24 & 76 & 53 & $718 \pm 24$ \\
DA-47 & 104 & 46 & 84
\end{tabular}

${ }^{*} p<0.05$ (compared to DA-47); Newman-Keuls Multiple Comparison Tests.

the brain (right Nissl versus right Schmorl's) indicated that the counts of adjacent sections with different staining procedures resulted in very similar counts throughout the extent of the nucleus (left side: Pearson's $r=0.99, p<0.001$; right side: $r=$ $0.98, p<0.001)$. Also, these counts were determined using $250 \times$ magnification on Nissl sections and $98 \times$ magnification on Schmorl's sections. It was somewhat faster counting cells using the lower-power magnification; however, neither the magnification nor the staining method influenced the distribution of cells that was determined.

The distribution of LC cells on the right and left sides of the brain was very similar across the 4 brains examined (Fig. 6). The number of LC and SC cells was counted on both sides of the brain in every 16 th section throughout the rostrocaudal extent of the nucleus. The cell-count distributions were illustrated relative to a common neuroanatomical landmark, the frenulum (located on the midline dorsal surface of the brain, just caudal to the inferior colliculus; see Fig. $2 A$ ), so that the pattern of cells could be compared to that of a standard landmark. In each brain, cell frequency was highest in the caudal portion of the nucleus and decreased as the nucleus progressed rostrally.

The left and right frequency distributions of LC cells were bilaterally symmetrical. In fact, in each of the 4 brains there was only a $3 \%$ average difference in the observed number of
Figure 4. The number of LC cells in serial adjacent selections in brain DA39. The number of cells is illustrated from the most caudal level of the nucleus $(0)$ to a more rostral level $(60)$ These counts are not corrected for splitcell error. Also shown is a regression line fitted to these data.

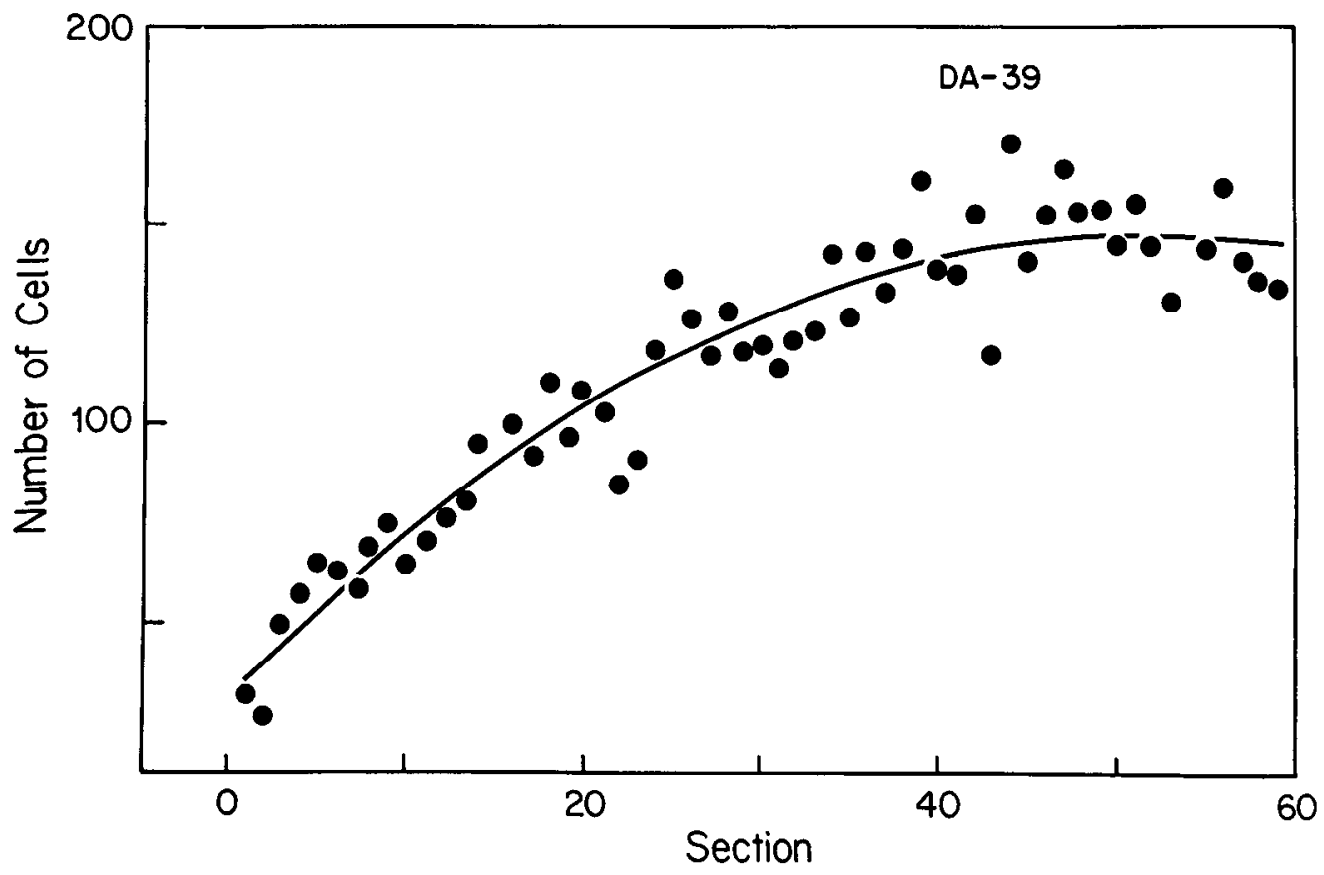




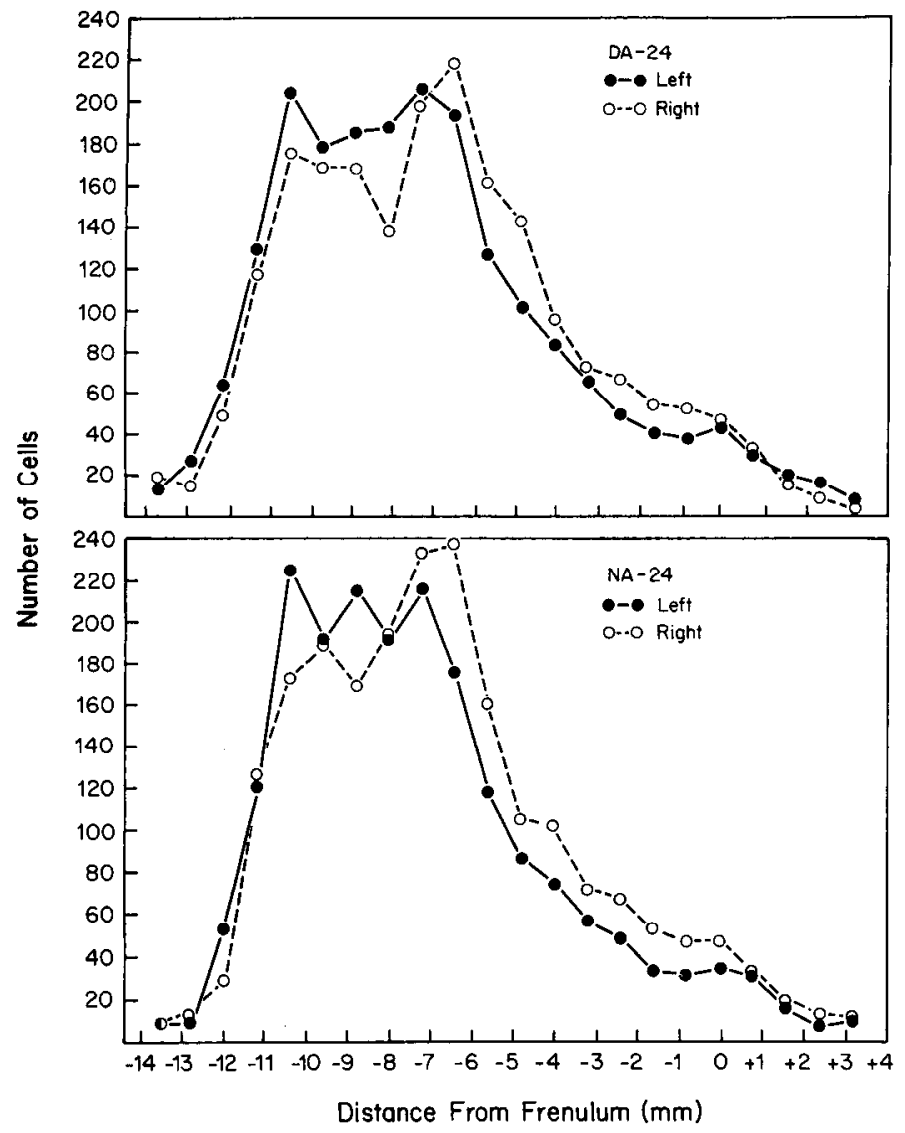

Figure 5. Similarity in the distributions of LC cells stained with different methods and counted in adjacent sections. Both graphs illustrate the distribution of LC cell frequencies from brain DA-24 on both sides of the brain, with reference to the position of the frenulum. Top, Sections stained with cresyl violet and counted using $250 \times$ magnification. Bottom, Adjacent sections, also separated by $0.8 \mathrm{~mm}$, stained with Schmorl's ferricyanide and counted with $98 \times$ magnification. These counts are not corrected for split-cell error.

cells on the 2 sides of the brain. Correlation coefficients were used to examine the similarities in cell-frequency distributions of the right and left nuclei. There was a highly significant correlation between the 2 distributions in each brain (DA-24: Pearson's $r=0.95, p<0.001$; DA-34: $r=0.91, p<0.001$; DA39: $r=0.94, p<0.001$; DA-47: $r=0.95, p<0.001)$. The LC cells in brain DA-24 were also counted in sections stained with Schmorl's ferricyanide and the correlation between cell frequencies was also highly significant (Pearson's $r=0.96, p<$ $0.001)$.

Table 4 shows the number of LC cells in the 4 coronally sectioned brains. The total number of cells counted in the right and left LC ranged from an average of 102 cells/section in the youngest brain to 50 cells/section in the oldest brain. A polynomial regression analysis was performed on the distribution of cell counts per section, and the equations that described the curve were used to predict the average number of cells per section. This average was based on the predicted values for every $50-\mu \mathrm{m}$-thick section through the nucleus (337 sections in the case of all brains except for DA-47, in which there were 257 total sections through the nucleus). By multiplying the mean predicted values by the total number of sections through each nucleus, the total number of cells can be determined. However,
Table 3. Accuracy of section sampling procedures

\begin{tabular}{lll} 
& $\begin{array}{l}\text { Mean observed } \\
\text { values }\end{array}$ & $\begin{array}{l}\text { Mean } \\
\text { predicted } \\
\text { values }\end{array}$ \\
\hline Every section & 108.00 & 108.00 \\
Every 4th section & 106.85 & 107.78 \\
Every 8th section & 107.00 & 109.75 \\
Every 16th section & 100.00 & 103.52
\end{tabular}

Forty-nine consecutive sections were examined using a polynomial regression analysis, and the observed and predicted means of the number of LC cells per section were 108 . By varying the number of sections sampled through these 49 sections, different observed and predicted means were determined.

since the same cell could be counted twice in adjacent sections, it was necessary to correct for split-cell error, using the equation $N i=n i \times t /(t+d)$, where $N i=$ the number of cells present, $n i=$ the number of cells counted, $t=$ section thickness, and $d=$ the diameter of the cell (Konigsmark, 1970). The diameter of the cell was calculated from the cell area data of Table 2, making the assumption that the cells were spherical. In several sections we empirically examined the split-cell error in counting. We generated digitized images of an LC field (250 $\times$ magnification) in one section and superirimposed it upon the live video view of the same field in an adjacent section after carefully aligning the sections with blood vessels common to both fields. We observed that there was an average of $35 \%$ double-counted cells. Cells counted as overlapping in adjacent fields were observed to be pieces of the same cell in 2 sections and not 2 different cells occupying the same neuroanatomical position. This value is $5 \%$ less than that determined using the formula from Konigsmark (1970). Using this empirically derived correction factor (35\%), the total estimated number of LC + SC cells in one hemisphere ranged from 8953 to 23,000 . The right side of the brain uniformly had more cells than the left side; however, the magnitude of the difference was small (from 2 to $12 \%$ ).

Figure 7 shows computer reconstructions of the 3-dimensional distribution of LC cells viewed from 2 different angles. In the coronal reconstruction, the view is from a position parallel to the long axis of the brain stem and $45^{\circ}$ above the horizontal plane. The sagittal reconstruction shows the right side of the brain, and the view is from a position perpendicular to the long axis of the brain stem at the midhorizontal level. Each LC cell appears as a yellow sphere, $200 \mu \mathrm{m}$ in diameter. Although the somata are smaller than this, the dendrites extend for a considerable distance so that this size does not overestimate the soma/ dendritic area (Swanson, 1976). These reconstructions allow an appreciation of the spatial distribution of LC cells within the dorsolateral pontinc tegmentum. The cells can bc scen to begin rostrally at the level of the inferior colliculus and end at the level of the widest portion of the fourth ventricle. The nucleus is displaced laterally by the opening of the cerebral aqueduct into the fullest extent of the fourth ventricle. The nucleus, viewed from a sagittal position, is composed of a relatively straight line of cells from rostral to caudal.

Quantification of the spatial distribution of cells is made possible by the cell-frequency maps. Five levels of cell frequency were chosen; areas of highest cell frequency are illustrated by red (2561-3200 cells $/ \mathrm{mm}^{2}$ ) and of lowest cell frequency by white (1-640 cells $/ \mathrm{mm}^{2}$, and these numbers are corrected for splitcell error. Figures 8 and 9 show cell-frequency maps from 5 

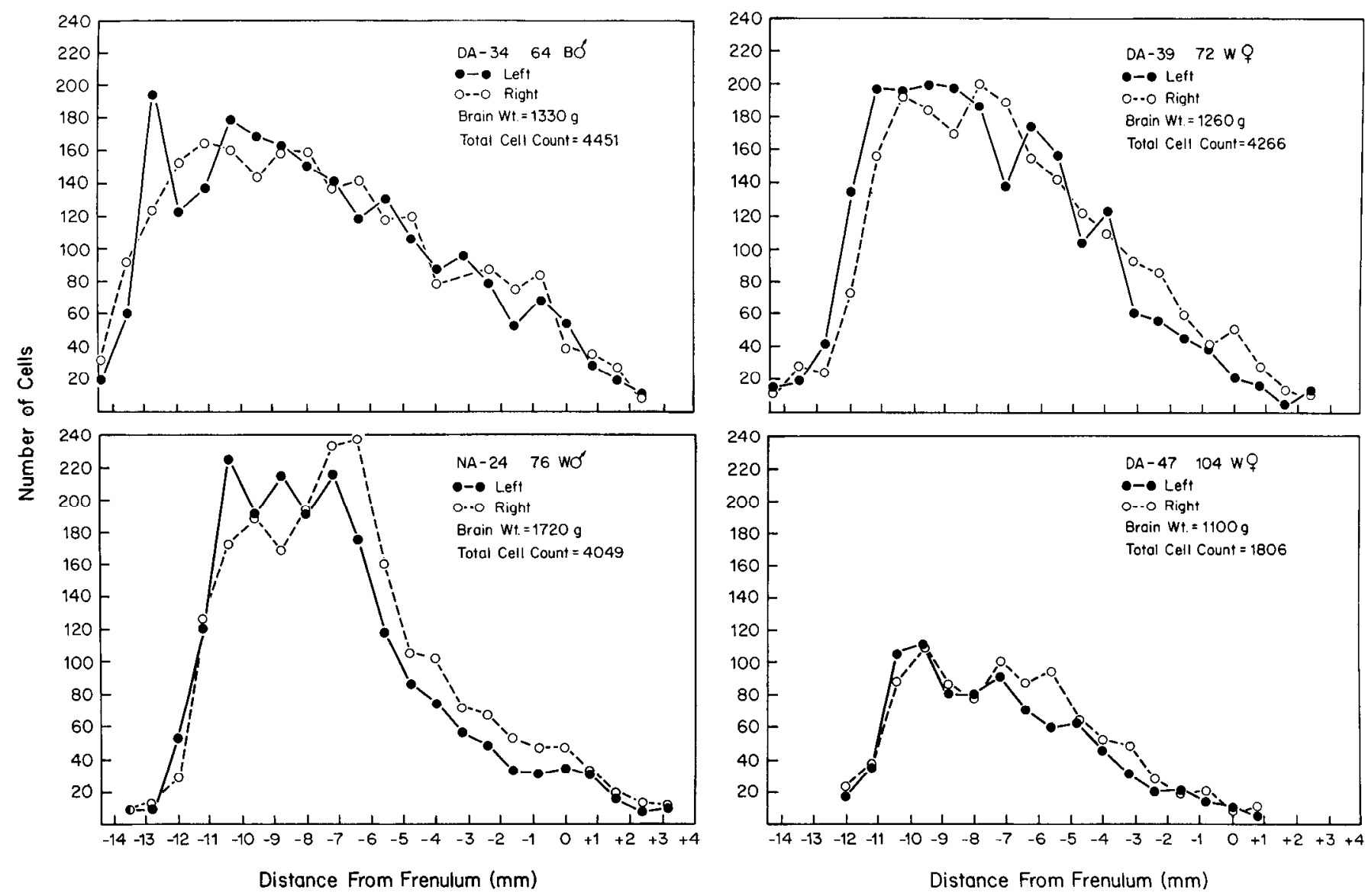

Figure 6. The number of LC cells counted per section as a function of the rostrocaudal position within the nucleus. The left and right nuclei are illustrated for 4 brains. The total number of cells counted per brain ranged from 4451 cells in DA-34 to 1806 cells in DA- 47 . The section " 0 mm" is through the frenulum with "+" numbers being rostral and "- " numbers caudal to the frenulum. Note the bilateral symmetry of the cell-frequency distributions within each brain.

brains ( 4 cut coronally and one sagittally). Each map indicates the distribution of LC cells relative to the position of the frenulum. The highest frequency of cells is uniformly located within the central portion of the nucleus at the middle to caudal level. Although the left and right nuclei have an overall similarity, there are some bilateral differences in the cell-frequency topographies. The most obvious differences between the brains are in the absence of the higher cell-frequency regions in the 104 year old compared to the younger brains, in the overall lengths of the nuclei, and in the distances between the left and right nuclei. Table 5 shows the areas occupied by each of the 5 cell-frequency regions in each of the 5 brains. The total area of the nucleus ranges from 32.8 to $17.2 \mathrm{~mm}^{2}$ and there was little difference in this area between the 2 sides of the brain.

\section{Discussion}

\section{$L C$ cell characteristics}

The noradrenergic neurons of the $L C$ are readily identifiable by their neuromelanin pigment content. This pigment is found within all of the catecholamine-containing nuclei in the human brain, and it has been used as a natural marker for these neurons (Bazelon et al., 1967; Bogerts, 1981; Saper and Petito, 1982). Nobin and Björklund (1973) found neuromelanin pigment within catecholamine fluorescent cells in the human fetus, and Pearson et al. (1983) have reported the presence of the catecholaminesynthesizing enzyme tyrosine hydroxylase within human LC neurons, in addition to neuromelanin pigment. This pigment is also present in nonhuman primates, and it has been used to map the location of LC neurons in the macaque brain (German and Bowden, 1975). Iversen et al. (1983) have shown that counting neuromelanin-containing and dopamine- $\beta$-hydroxylase-containing LC cells gives identical cell counts in the human brain. It seems clear that neuromelanin pigment serves as a reliable marker for primate LC noradrenergic neurons.

The LC cells are oval and fusiform in shape, and their size decreases with age. In the 64-year-old, the largest cells averaged over $800 \mu \mathrm{m}^{2}$ in area. In the 104-year-old, however, the cell area averaged $718 \mu \mathrm{m}^{2}$. It has been reported that neuromelanin

Figure 7. Three-dimensional reconstructions of the LC viewed from 2 different angles. Top, A reconstruction from a coronally sectioned brain (DA-24). Cells are shown as yellow spheres, and rostral is in the foreground. Note that as the cells progress caudally they are displaced laterally by the opening of the fourth ventricle. Subcoeruleus cells can be seen extending ventrolaterally from the caudal LC. The view is from $45^{\circ}$ above the horizontal plane. Bottom, A reconstruction from a sagittally sectioned brain (DA-33). The beginning of the nucleus can be seen at the level of the inferior colliculus $(I C)$. The view is from a point parallel to the midhorizontal plane. $D$, dorsal; $C$, caudal; $R$, rostral; $S M V$, superior medullary velum. 


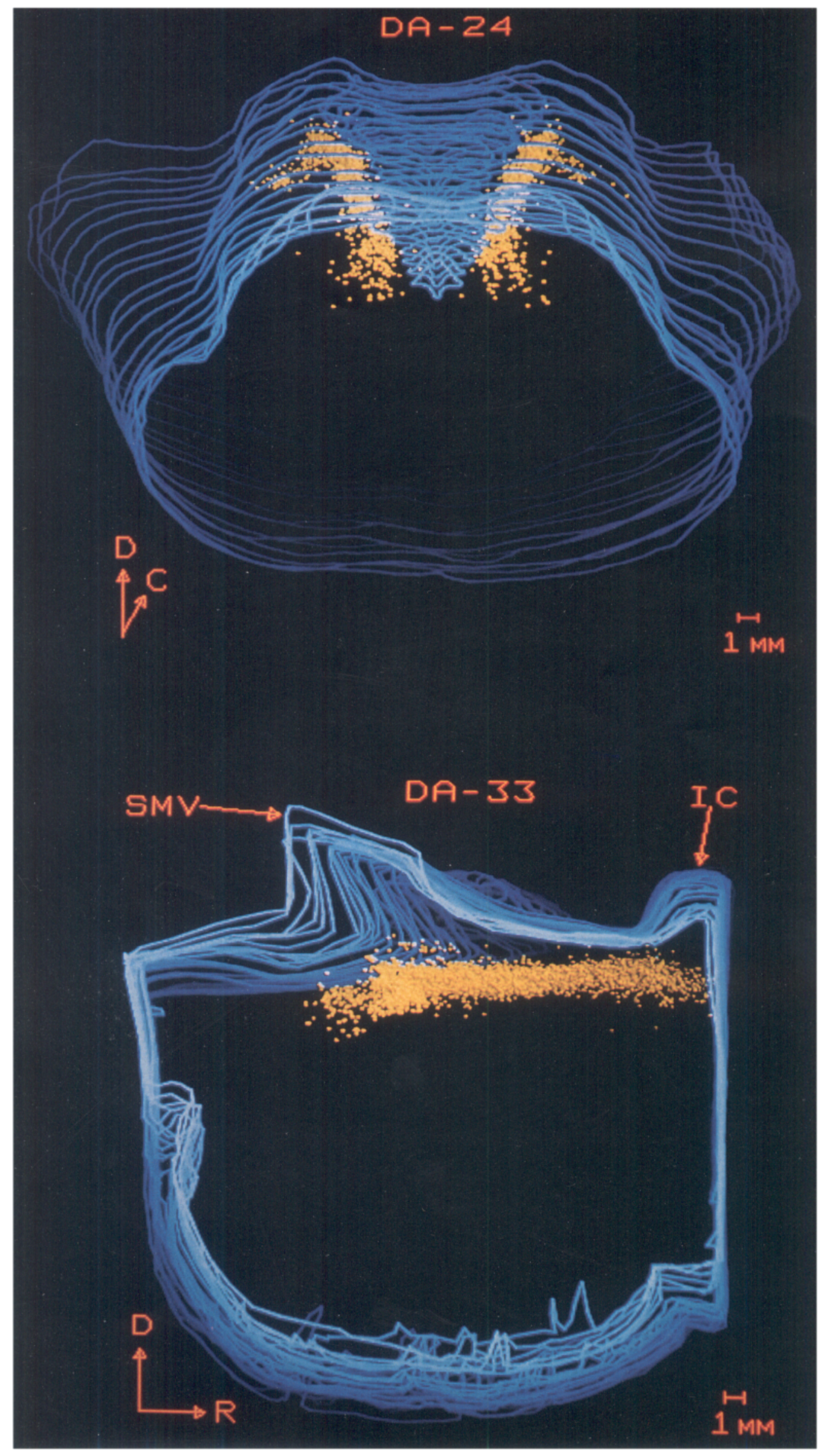




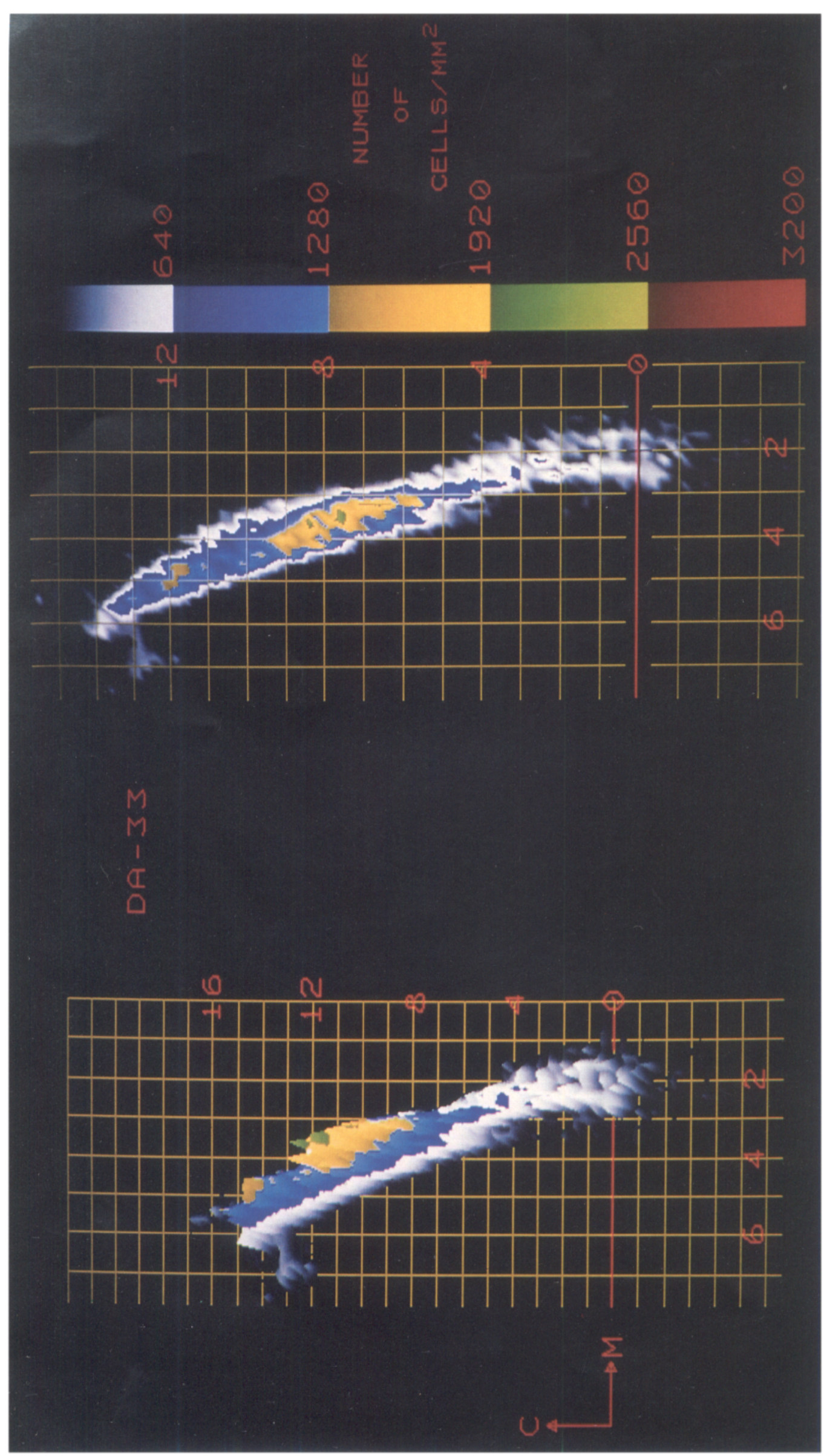

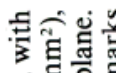

结古

票焉

은

펑유능

공

능

ช્d

ह

స्ञ

刍设

응 중

क्ष

踏

ธี

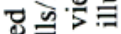

过 0.

药

흉을

술일

드렁ㅇ

을 䒠

苯氙寻

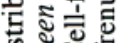

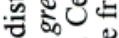

넌도

西牙宁

ฮิํํ유

토ㅇㅠㅛ

등

घ่웡

สูํํㄹ

응 के

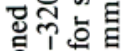

항-

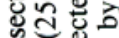

خ녕

전 8

․ㅡㄴ 융

क्ष

๙

토ำ

结寻

ô.

해응

䨌

금요

可远

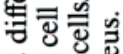

궁워을

해이

보른

ठㄴㅇㅇ

ฮี

ᄀ 흘

טฐ⿱

G氙密

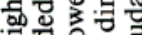

등을 쟁

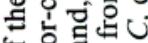
흥 등



氜. 틀.

줄 토

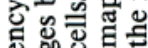

屯용

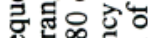

次资

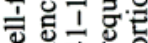

$\checkmark$ 教

. 包

事

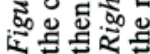




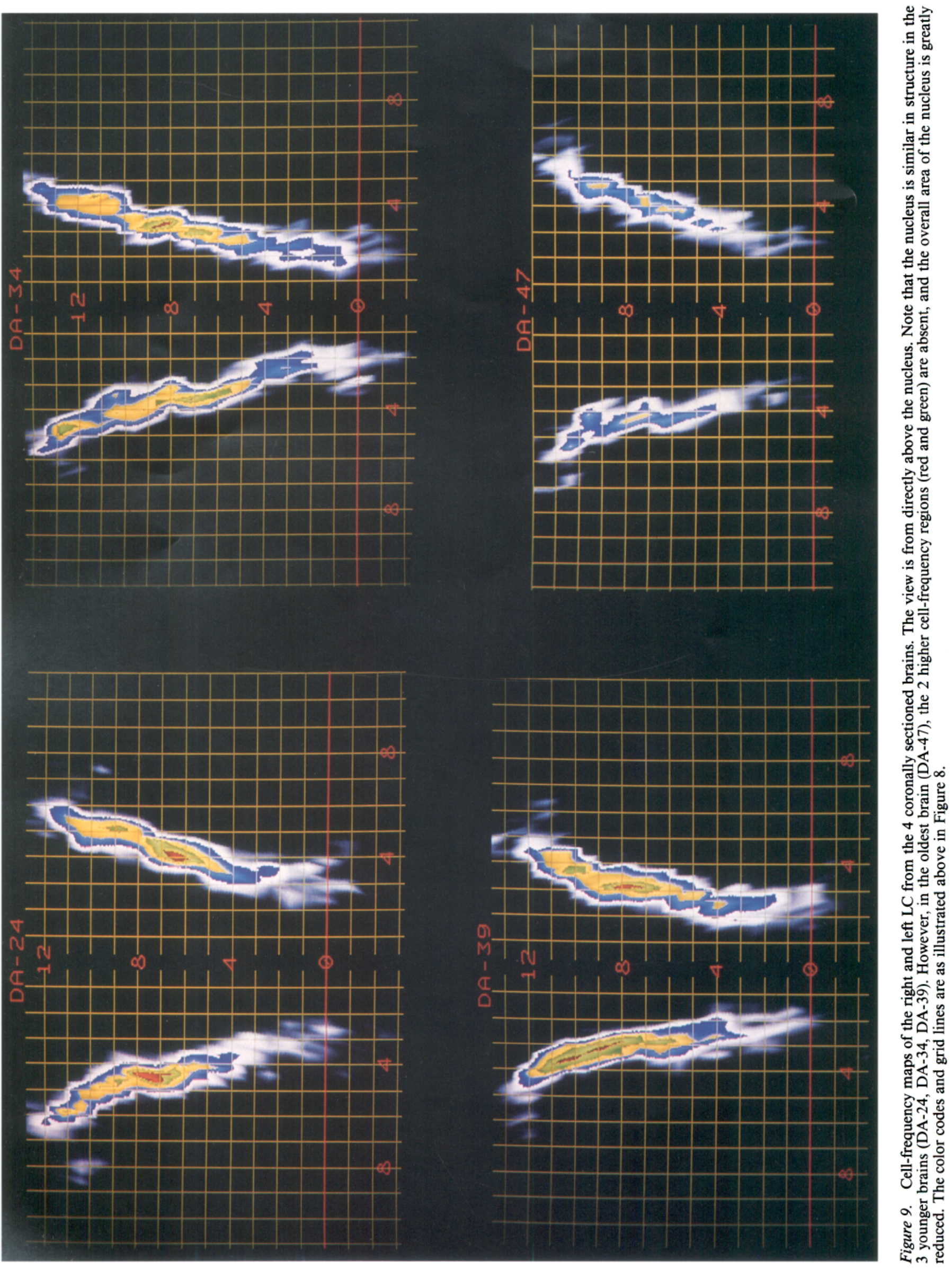


Table 4. LC cell number

\begin{tabular}{|c|c|c|c|c|c|c|c|}
\hline \multirow[b]{2}{*}{ Brain } & \multirow{2}{*}{$\begin{array}{l}\text { Age } \\
\text { (years) }\end{array}$} & \multicolumn{2}{|c|}{$\begin{array}{l}\text { Mean observed } \\
\text { values }^{a}\end{array}$} & \multicolumn{2}{|c|}{$\begin{array}{l}\text { Mean predicted } \\
\text { values }^{b}\end{array}$} & \multicolumn{2}{|c|}{ Total LC cells ${ }^{c}$} \\
\hline & & Left & Right & Left & Right & Left & Right \\
\hline DA-34 & 64 & 100 & 102 & 103 & 105 & 22,562 & 23,000 \\
\hline DA-39 & 72 & 97 & 97 & 101 & 102 & 21,124 & 22,343 \\
\hline DA-24n & 76 & 89 & 95 & 93 & 100 & 20,371 & 21,905 \\
\hline DA-24s & 76 & 91 & 92 & 95 & 97 & 20,809 & 21,247 \\
\hline DA-47 & 104 & 50 & 56 & 52 & 58 & 8953 & 9987 \\
\hline
\end{tabular}

${ }^{a}$ Average number of LC cells per section. Brain DA-24 was counted both with Nissl stain (24n) and Schmorl's stain (24s).

"Average number of LC cells per section predicted from a polynomial regression analysis.

Total number of LC cells determined after correction for split-cell error. Correction factor $=0.65$ for every brain except DA-47, in which it was 0.67 .

pigment accumulates within these neurons in a linear fashion from the first to the 6th decade of life, as does the size of the LC somata; after the 6th decade, cell sizes decrease, apparently because of loss of the largest cells (Mann and Yates, 1974; Graham, 1979). Neuromelanin appears to be a waste product of catecholamine metabolism, derived from the oxidation of catecholamines and related compounds to quinones. Some investigators have proposed that neuromelanin is cytotoxic in that its accretion mechanically disrupts the microanatomy of intracellular membranes (Mann and Yates, 1974). Others have proposed that oxidation of catecholamines produces hydrogen peroxide, superoxide anions, and hydroxyl radicals, which are cytotoxic to these cells (Graham, 1979).

The LC neurons begin rostrally within the ventrolateral central gray substance, at the level of the inferior colliculus, and extend caudally to a position in the lateral wall of the fourth ventricle. In the brains aged $60,64,72$, and 76 years, the nucleus spanned a distance of from 16 to $17 \mathrm{~mm}$. In the oldest brain the nucleus spanned a distance of only $13 \mathrm{~mm}$. This distance assumes that the beginning and end of the nucleus is defined by the presence of at least $5 \mathrm{LC}$ cells per section. Such a definition is necessary since, caudally, the LC cells merge with the noradrenergic cells of nucleus A4 (Moore and Bloom, 1979).

\section{Cell-counting accuracy}

The reliability of a human observer in identifying the LC cells was verified in several ways. First, since the right and left nuclei

Table 5. Areas of LC cell frequency ${ }^{a}$

\begin{tabular}{llllllll} 
& & \multicolumn{7}{l}{ Area $\left(\mathrm{mm}^{2}\right)$} \\
\cline { 3 - 8 } Brain & Side & White & Blue & Yellow & Green & Red & Total \\
\hline DA-33 & Right & 21.3 & 6.3 & 2.3 & 0.2 & 0.0 & 30.1 \\
DA-34 & Right & 18.6 & 7.2 & 3.8 & 1.1 & 0.1 & 30.8 \\
& Left & 17.6 & 7.6 & 4.1 & 0.9 & 0.1 & 30.3 \\
DA-39 & Right & 17.1 & 4.4 & 2.6 & 2.6 & 0.4 & 27.1 \\
& Left & 18.8 & 5.8 & 3.8 & 1.1 & 0.2 & 29.7 \\
DA-24 & Right & 24.1 & 4.5 & 3.0 & 0.8 & 0.4 & 32.8 \\
& Left & 20.6 & 5.0 & 3.1 & 1.3 & 0.3 & 30.3 \\
DA-47 & Right & 12.8 & 4.1 & 0.3 & 0.0 & 0.0 & 17.2 \\
& Left & 15.9 & 3.7 & 0.6 & 0.0 & 0.0 & 20.2 \\
& & & &
\end{tabular}

areas represent regions on the horizontal plane containing certain frequencies of LC neurons. These areas are illustrated in Figures 8 and 9. White areas, $1-640$ cells $/ \mathrm{mm}^{2}$; blue areas, $641-1280$ cells $/ \mathrm{mm}^{2}$; yellow areas, $1281-1920 \mathrm{cells} / \mathrm{mm}^{2}$; green areas, 1921-2560 cells $/ \mathrm{mm}^{2}$; and red areas, $2561-3200 \mathrm{cells} / \mathrm{mm}^{2}$. in each brain exhibited similar distributions of cell frequencies, this served as a check as to whether cell identification criteria were consistently applied. Second, some phase shift was observed in the distribution of cell frequencies between the left and right sides of the brain (see brains DA-39 and NA-24 in Fig. 6). This is because the brain sections were not always cut in a bilaterally symmetrical plane perpendicular to the long axis of the brain stem. This disparity (not greater than $5^{\circ}$ ) is a reflection of the accuracy with which a block of brain stem tissue can be cut and mounted onto a microtome stage. The fact that the distributions were symmetrical, although slightly phaseshifted, indicates that the symmetry must exist in the brain and is not somehow related to observer bias. Third, when one brain was counted twice, using an adjacent series of sections separated by $0.8 \mathrm{~mm}$, the distribution of cell frequencies was remarkably similar. These 2 series were counted using different stains (Nissl and Schmorl's ferricyanide) and different microscope magnifications. This similarity indicates that reliable counts were obtained from the same population of cells.

The distribution of LC cells can be accurately described by sampling sections separated by $0.8 \mathrm{~mm}$. The primary evidence for this is that, after counting 59 consecutive sections through the caudal LC, the average variability of cell counts about a regression line fitted to the cell-frequency distribution was \pm 10 cells. When the entire rostrocaudal extent of the $\mathrm{LC}$ was counted in sections separated by $0.8 \mathrm{~mm}$, there was very similar variability, i.e., \pm 11 cells. Thus, there is the same variability in cell counts when each section is counted as when every 16 th section is counted. The conclusion is further supported by the finding that the distribution of cells is similar across brains (Fig. 6) and within the one brain counted twice in adjacent series (Fig. 5). If marked differences in cell number occurred at intervals of less than $0.8 \mathrm{~mm}$, then the distribution of cells would be quite different between brains. The distributions, however, were similar. Finally, when a polynomial regression analysis was used to predict the total number of cells from samples taken at $0.8 \mathrm{~mm}$ intervals, there was less than a $5 \%$ disparity between the predicted and observed values.

There were an estimated 20,809-22,562 cells in the left LC, spanning a $16-17 \mathrm{~mm}$ rostrocaudal length in the 4 brains, aged 60-76 years. These values agree quite well with the total LC cell counts obtained by Vijayshankar and Brody (1979). They reported the total number of cells in LC, determined by counting every 10 th $10-\mu \mathrm{m}$-thick paraffin section in 24 brains. They found slightly over 18,000 cells in the left LC in 3 of 7 brains in the 
6th decade of life, and the nucleus had a rostrocaudal length of just under $12 \mathrm{~mm}$. Although they counted a somewhat smaller extent of the LC-subcoeruleus (SC) complex than is reported in the present study, their numbers are similar to those reported here.

\section{Bilateral symmetry of the $L C$}

There was less than a $3 \%$ difference in total LC cell number between the 2 sides of the brain in the 4 brains examined. In an additional 5 brains that we have examined (ages ranging from 5 to 24 years), the left-right difference in total cell number ranged from 0.5 to $3.6 \%$. Likewise, in the brains examined by Vijayshankar and Brody (1979), there was less than a $1 \%$ difference in the total number of LC cells on each side of the brain. The present data extend these findings by demonstrating that not only is the total cell number similar for the 2 sides of the brain, but the distribution of cells throughout the nucleus is also bilaterally symmetrical. This was indicated by the highly significant correlation coefficients for the left and right sides of the brain in each of the 4 brains (the smallest correlation coefficient was 0.91).

\section{LC cellular distribution}

The present results indicate, for the first time, that there are similarities and differences in the overall distributions of LC cells from brain to brain. In all previous studies involving LC cell counts, there were either very few sections counted or only total cell counts were reported. In the present study we found that in each brain the cell frequency was highest in the caudal portion of the nucleus and then decreased rostrally (Fig. 6). However, there were also individual differences in the shapes of the frequency distributions. The significance of these differences must await analysis of larger numbers of brains.

As seen in the 3-dimensional visualizations, the LC cells begin rostrally at the level of the inferior colliculus and form a tube that is displaced laterally by the opening of the cerebral aqueduct into the fourth ventricle (Fig. 7). The visualization techniques were used on tissue cut in both coronal and sagittal planes to produce 2 different views of the nucleus. It should be noted that after careful alignment procedures were carried out, both views of the LC were quite similar in appearance. This finding served as an additional check on the validity of our alignment methodology. Our alignment and 3-dimensional reconstruction techniques were similar to those previously used by Foote et al. (1980) to reconstruct the LC in the rat; however, we used additional techniques for illustrating cells as spheres, plus shading and colorization in order to provide the most detailed information per picture (these latter methods were previously described by Schlusselberg et al., 1982).

Quantification of the 3-dimensional distribution of LC cells is made possible by the 2-dimensional cell-frequency maps (Figs. 8,9 ; Table 5). We have used thesc tcchniques previously to examine the distribution of midbrain dopaminergic neurons in humans and rodents (German et al., 1983, 1985). Cell-frequency maps indicate similarities and differences in the LC in the 5 brains examined. Although there is considerable bilateral symmetry between the left and right nuclei, the 2 sides do not appear identical. For example, the total horizontal areas of the left and right LC can be very similar, as in the case of DA-34 (30.3 versus $30.8 \mathrm{~mm}^{2}$ ), or somewhat different, as in the case of DA39 (29.7 versus $27.1 \mathrm{~mm}^{2}$ ). This may represent individual differences, or cell clustering may be a normal feature of the nu- cleus. More brains will have to be examined before this question can be resolved. Of particular note is the relative sparseness of cells and shortening of the rostrocaudal length of the LC in the oldest brain (104 years old).

The major limitation in the accuracy of the present, and all other (e.g., Foote et al., 1980; Hibbard et al., 1987) 2- and 3-dimensional reconstructions is the uncertainty of the exact angle at which the sections were cut. As mentioned above, we calculated that there was as much as a $5^{\circ}$ variation in the left/ right symmetry in the coronal plane of section and undoubtedly a comparable variability in the dorsoventral plane of section. This variation occurred in spite of the fact that every attempt was made to place the tissue block on the microtome stage in a plane that was perpendicular to the long axis of the brain stem. Although such variation is tolerable for the present purposes, we are currently seeking a solution to this problem based on improved techniques for positioning the tissue block on the microtome stage, along with improved determination of the positions of multiple external landmarks.

\section{Future utility}

In many studies of the human LC, only a small fraction (i.e., 1 $\mathrm{mm}$ ) of the nucleus has been examined (e.g., Mann et al., 1980, 1983; Tomlinson et al., 1981; Mann and Yates, 1983). However, aging and disease may not affect the entire nucleus in the same way. The LC projects to the forebrain, cerebellum, and spinal cord in a topographic, although not point-to-point, fashion (Hancock and Fougerousse, 1976; Moore and Bloom, 1979; Waterhouse et al., 1983; Westlund et al., 1984; Loughlin et al., 1986). It is possible that aging and various diseases disproportionately affect certain of the LC projection neurons. For example, it has been reported recently that in Alzheimer's disease, the rostral portion of the $\mathrm{LC}$ is more severely reduced in cell number than is the caudal portion of the nucleus (Lockhart et al., 1984; Marcyniuk et al., 1986). Because the rostral and dorsal LC cells project to cortical/forebrain regions, and the caudal and ventral LC and SC cells project to the spinal cord, Alzheimer's disease may specifically affect the cortical/forebrain-projecting neurons (German et al., 1987). It is clear that an examination of the entire LC by procedures like those described here will be necessary in order to fully appreciate the effects of normal aging and disease on this nucleus. The methods presented in this paper provide a reliable and accurate way in which to quantify the cellular distribution of neurons within the LC or within any nucleus.

\section{References}

Barden, H. (1969) The histochemical relationship of neuromelanin and lipofuscin. J. Neuropathol. Exp. Neurol. 28: 419-441.

Bazelon, M., G. M. Fenichel, and J. Randall (1967) Studies on neuromelanin. I. A melanin system in the human adult brainstem. Neurology 17: 512-519.

Bogerts, B. (1981) A brainstem atlas of catecholaminergic neurons in man, using melanin as a natural marker. J. Comp. Neurol. 197: 6380.

Bowden, D. M., D. C. German, and W. D. Poynter (1978) An autoradiographic, semistereotaxic mapping of major projections from locus coeruleus and adjacent nuclei in Macaca mulatta. Brain Res. 145 : 257-276.

Choi, B. H., D. S. Antanitus, and L. W. Lapham (1975) Fluorescence histochemical and ultrastructural studies of locus coeruleus of human fetal brain. J. Neuropathol. Exp. Neurol. 34: 507-516.

Dahlstrom, A., and K. Fuxe (1964) Evidence for the existence of monoamine-containing neurons in the central nervous system. I. 
Demonstration of monoamines in the cell bodies of brain stem neurons. Acta Physiol. Scand. (Suppl. 232) 62: 1-55.

Fenichel, G. M., and M. Bazelon (1968) Studies on neuromelanin. II. Melanin in the brainstems of infants and children. Neurology 18 . 817-820.

Foley, J. M., and D. Baxter (1958) On the nature of pigment granules in the cells of the locus coeruleus and substantia nigra. J. Neuropathol. Exp. Neurol. 17: 586-598.

Foote, S. L., S. E. Loughlin, P. S. Cohen, F. E. Bloom, and R. B. Livingston (1980) Accurate three-dimensional reconstruction of neuronal distributions in brain: Reconstruction of the rat nucleus coeruleus. J. Neurosci. Methods 3: 159-173.

Forno, L. S. (1978) The locus coeruleus in Alzheimer's disease. J. Neuropathol. Exp. Neurol. 37: 614.

Freedman, R., S. L. Foote, and F. E. Bloom (1975) Histochemical characterization of a neocortical projection of the nucleus locus coeruleus in the squirrel monkey. J. Comp. Neurol. 164: 209-231.

German, D. C., and D. M. Bowden (1975) Locus coeruleus in rhesus monkey (Macaca mulatta): A combined histochemical fluorescence, Nissl and silver study. J. Comp. Neurol. 161: 19-29.

German, D. C., D. S. Schlusselberg, and D. J. Woodward (1983) Threedimensional computer reconstruction of midbrain dopaminergic neuronal populations: From mouse to man. J. Neural Trans. 57: 243254.

German, D. C., B. S. Walker, K. McDermott, W. K. Smith, D. S. Schlusselberg, and D. J. Woodward (1985) Three-dimensional computer reconstructions of catecholaminergic neuronal populations in man. In Quantitative Neuroanatomy in Transmitter Research, L. F. Agnati and K. Fuxe, eds., pp. 113-125, Macmillan, London.

German, D. C., C. L. White, and D. R. Sparkman (1987) Alzheimer's disease: Neurofibrillary tangles in nuclei that project to the cerebral cortex. Neuroscience 21: 305-312.

Graham, D. G. (1979) On the origin and significance of neuromelanin. Arch. Pathol. Lab. Med. 103: 359-362.

Hancock, M. B., and C. L. Fougerousse (1976) Spinal projections from the nucleus locus coeruleus and nucleus subcoeruleus in the cat and monkey as demonstrated by the retrograde transport of horseradish peroxidase. Brain Res. Bull. 1: 229-234.

Hibbard, L. S., J. S. McGlone, D. W. Davis, and R. A. Hawkins (1987) Three-dimensional representation and analysis of brain energy metabolism. Science 236: 1641-1646.

Hornykiewicz, O. (1979) Brain dopamine in Parkinson's disease and other related neurological disturbances. In The Neurobiology of Dopamine, A. S. Horn, J. Korf, and B. H. C. Westerink, eds., pp. 633654, Academic, New York.

Iversen, L. L., M. N. Rossor, G. P. Reynolds, R. Hills, M. Roth, C. Q. Mountjoy, S. L. Foote, J. H. Morrison, and F. E. Bloom (1983) Loss of pigmented dopamine- $\beta$-hydroxylase positive cells from locus coeruleus in senile dementia of Alzheimer's type. Neurosci. Lett. 39: 95100 .

Konigsmark, B. W. (1970) Methods for the counting of neurons. In Contemporary Research Methods in Neuroanatomy, W. J. H. Nauta and S. O. E. Ebbeson, eds., pp. 315-340, Springer-Verlag, New York.

Lillie, R. D. (1954) In Histopathologic Technic and Practical Histochemistry, 2nd Ed., Blakiston, New York.

Lockhart, M. P., C. J. Gibson, and M. J. Ball (1984) Topographical loss of locus coeruleus cells in Alzheimer's disease. Soc. Neurosci. Abstr. 10: 995 .

Loughlin, S. E., S. L. Foote, and F. E. Bloom (1986) Efferent projections of nucleus locus coeruleus: Topographic organization of cells of origin demonstrated by three-dimensional reconstructions. Neuroscience 18: 291-306.
Mann, D. M. A., and P. O. Yates (1974) Lipoprotein pigments- their relationship to aging in the human nervous system. II. The melanin content of pigmented nerve cells. Brain 97: 489-498.

Mann, D. M. A., and P. O. Yates (1983) Pathological basis for neurotransmitter changes in Parkinson's disease. Neuropathol. Appl. Neurobiol. 9: 3-19.

Mann, D. M. A., J. Lincoln, P. O. Yates, J. E. Stamp, and S. Toper (1980) Changes in the monoamine containing neurones of the human CNS in senile dementia. Br. J. Psychiatry 136: 533-541.

Mann, D. M. A., P. O. Yates, and J. Hawkes (1983) The pathology of the human locus coeruleus. Clin. Neuropathol. 2: 1-7.

Marcyniuk, B., D. M. A. Mann, and P. O. Yates (1986) Loss of nerve cells from locus coeruleus in Alzheimer's disease is topographically arranged. Neurosci. Lett. 64: 247-252.

Moore, R. Y., and F. E. Bloom (1979) Central catecholamine neuron systems: Anatomy and physiology of the norepinephrine and epinephrine systems. Annu. Rev. Neurosci. 2: 113-168.

Nobin, A., and A. Björklund (1973) Topography of the monoamine neuron systems in the human brain as revealed in fetuses. Acta Physiol. Scand. (Suppl. 388): 1-40.

Olson, L., B. Nystrom, and A. Seiger (1973) Monoamine fluorescence histochemistry of human post mortem brain. Brain Res. 63: 231247.

Pearson, J., M. Goldstein, K. Markey, and L. Brandeis (1983) Human brainstem catecholamine neuronal anatomy as indicated by immunocytochemistry with antibodies to tyrosine hydroxylase. Neuroscience $8:$ 3-32.

Reil, J. C. (1809) Untersuchungen uber den Bau des grossen Gehirns im Menschen. Arch. Physiol. 9: 136-524.

Rogers, A. D., and G. Curzon (1975) Melanin formation by human brain in vitro. J. Neurochem. 24: 1123-1129.

Russell, C. V. (1955) The nucleus locus coeruleus (dorsolateralis tegmenti). Tex. Rep. Biol. Med. 13: 939-988.

Saper, C. B., and C. K. Petito (1982) Correspondence of melaninpigmented neurons in human brain with $\mathrm{Al}$-A14 catecholamine cell groups. Brain 105: 87-101

Schlusselberg, D. S., W. K. Smith, M. H. Lewis, B. G. Culter, and D. J. Woodward (1982) A general system for computer based acquisition, analysis and display of medical image data. Proc. ACM, 1825 .

Swanson, L. W. (1976) The locus coeruleus: A cytoarchitcctonic, Golgi and immunohistochemical study in the albino rat. Brain Res. 110 . $39-56$.

Tomlinson, B. E., D. Irving, and G. Blessed (1981) Cell loss in the locus coeruleus in senile dementia of Alzheimer type. J. Neurol. Sci. 49: 419-428.

Ungerstedt, U. (1971) Stereotaxic mapping of the monoamine pathways in the rat brain. Acta Physiol. Scand. (Suppl. 367): 1-48.

Vijayshankar, N., and H. Brody (1979) A quantitative study of the pigmented neurons in the nuclei locus coeruleus and subcoeruleus in man as related to aging. J. Neuropathol. Exp. Neurol. 38: 490-497.

Waterhouse, B. D., C.-S. Lin, R. A. Burne, and D. J. Woodward (1983) The distribution of neocortical projection neurons in the locus coeruleus. J. Comp. Neurol. 217:418-431.

Wenzel, J., and K. Wenzel (1811) De Penitiori Structura Cerebri (quoted from Ziehen, 1920), pp. 168.

Westlund, K. N., R. M. Bowker, M. G. Ziegler, and J. D. Coulter (1984) Origins and terminations of descending noradrenergic projections to the spinal cord of monkey. Brain Res. 292: 1-16. 